\title{
Cobrança pelo uso da água do Rio São Francisco: a percepção socioambiental das populações beneficiadas pelos projetos
}

\section{Ana Cristina da Silveira ${ }^{1}$, Marília Carvalho de Melo $^{2}$ e Melchior Carlos do Nascimento}

\author{
${ }^{1}$ Universidade Vale do Rio Verde. Avenida Castelo Branco, 82. Chácara das Rosas. \\ Três Corações-MG, Brasil (CEP 37417-150). E-mail: ana_c_silveira@yahoo.com.br. \\ ${ }^{3}$ Universidade Federal de Alagoas. Instituto de Geografia, Desenvolvimento e Meio \\ Ambiente. Campus A. C. Simões. Maceió-AL, Brasil (CEP 57072-900).
}

Resumo. A cobrança pelo uso da água foi estabelecida por lei no Brasil em 1997, contudo, decorridas mais de duas décadas, a implementação deste instrumento de gestão de recursos hídricos e suas experiências ainda não foram amplamente difundidas. 0 processo de cobrança pelo uso da água na Bacia Hidrográfica do Rio São Francisco teve início em 2010 e a execução dos projetos com os recursos da cobrança começou a partir de 2012. Desde então, foram investidos mais de cem milhões de reais, mas os resultados alcançados não foram suficientemente avaliados. Assim sendo, o presente estudo buscou investigar os atores do sistema de gestão hídrica e beneficiários diretos dos projetos, com o objetivo de analisar a efetividade das ações, tendo como base a percepção social dos resultados de projetos financiados pelo Comitê. Foram estabelecidos critérios para a seleção dos projetos pesquisados e a coleta de dados foi feita por meio de questionários. Os resultados demonstraram avanços e oportunidades para a gestão de recursos hídricos da bacia hidrográfica do rio São Francisco, especialmente relacionadas ao aperfeiçoamento do instrumento da cobrança pelo uso da água e o aprimoramento da seleção e fiscalização dos projetos.

Palavras-chave: Rio São Francisco; Cobrança pelo uso da água; Percepção socioambiental; Gestão de recursos hídricos; Projeto hidroambiental.

Abstract. Charges for the use of water from the São Francisco River: The socio-environmental perception of the populations benefiting from the projects. The water use charge was established by law in Brazil, in 1997; however, after more than two decades, the implementation of this water resource management instrument and the experiences from its use have not yet been widely disseminated. The charge for water use in the São Francisco River Basin started in 2010 and the execution of projects using the collection resources started in 2012. Since then, more than one hundred million reais have been invested,
Recebido

29/07/2020

Aceito

$15 / 04 / 2021$

Publicado

$30 / 04 / 2021$

Acesso aberto

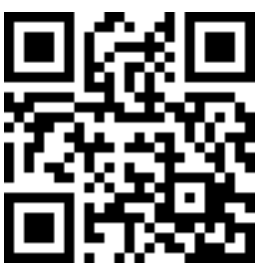

ORCID

(ㄱ) 0000-0003-0878-3129

Ana Cristina da

Silveira

D) 0000-0002-9789-2169

Marília Carvalho de Melo

D 0000-0002-6547-1829

Melchior Carlos do

Nascimento

ISSN 2359-1412/RBGAS-2020-0115/2021/8/18/27/415

Rev. Bras. Gest. Amb. Sustent.

http://revista.ecogestaobrasil.net 
but the results achieved have not been sufficiently evaluated. Therefore, this study sought to investigate the actors of the water management system and direct beneficiaries of the projects, with the aim of analyzing the effectiveness of the actions, based on the social perception of the results of projects financed by the Committee. Some criteria were established for the selection of research projects and data collection was carried out through questionnaires. The results showed advances and opportunities for the management of water resources in the São Francisco River Basin, especially related to the improvement of the instrument for water use charges and the improvement in the selection and monitoring of the projects.

Keywords: São Francisco River; Water use charges; Socioenvironmental perception; Water resource management; Hydroenvironmental project.

\section{Introdução}

A Política Nacional de Recursos Hídricos foi instituída pela Lei no 9.433/1997 (Brasil, 1997), que também criou o Sistema Nacional de Gerenciamento de Recursos Hídricos (SINGREH). Representou um marco institucional no Brasil, pois trouxe avanços importantes na ordenação territorial, planejamento e gestão dos recursos hídricos, com normas e padrões para a implementação de uma gestão democrática, descentralizada, integrada e planejada, envolvendo seus múltiplos usos e a gestão ambiental (Barcellos et al., 2011).

A cobrança pelo uso de recursos hídricos é um dos instrumentos de gestão previstos pela lei e visa a reconhecer a água como bem econômico, incentivar a racionalização do uso e obter recursos financeiros para realizar estudos, projetos e programas constantes nos planos de recursos hídricos (Brasil, 1997). São cobrados os usos da água sujeitos a outorga de direito de uso de recursos hídricos, principalmente os grandes usuários, como as concessionárias de água e esgoto, indústrias e atividades agropecuárias.

Brito e Aguiar (2019) destacam que a cobrança, além de servir como incentivo ao uso racional e desestímulo às condutas ambientalmente degradantes, também pode estimular o investimento em despoluição e encorajar a utilização de tecnologias limpas e poupadoras de recursos hídricos. De acordo com Kroeger et al. (2019) o gerenciamento de bacias hidrográficas pode ter amplo potencial para fornecer serviços hidrológicos de maneira econômica.

Conforme previsto na Lei no 9.433/1997, o comitê de bacia hidrográfica, dentre outras atribuições, é o responsável por estabelecer os mecanismos de cobrança e sugerir os valores a serem cobrados (Brasil, 1997). A metodologia de cobrança, após deliberada pelo comitê, é encaminhada ao conselho de recursos hídricos para aprovação. A agência de água (ou entidade delegatária) atua como secretaria executiva do comitê e desempenha atividades de apoio técnico e administrativo, sendo a responsável pela aplicação, fiscalização e prestação de contas dos recursos da cobrança.

A cobrança pelo uso da água é um instrumento de efetivação recente no Brasil. A sua implementação iniciou-se em 2003 no Rio Paraíba do Sul, em seguida nos Rios Piracicaba, Capivari e Jundiaí em 2006 (ANA, 2019). No Rio São Francisco o sistema de cobrança foi implementado no ano de 2010 de uma forma simples para que promovesse a 
aceitação dos usuários e a compreensão de todos os entes envolvidos no processo e na execução do instrumento (Assis et al., 2018).

As metodologias estabelecidas para a cobrança pelo uso da água são bastante similares, sendo concebidas pelos componentes: Captação, Consumo, Lançamento e Transposição (Finkler, 2015). A cobrança, no entanto, não deve ser esperada como a solução capaz de sanar mazelas cometidas durantes séculos sobre as águas da bacia (Magalhães Júnior e Nunes Júnior, 2009).

Segundo relatório da Organização para Cooperação e Desenvolvimento Econômico (OCDE, 2017), a cobrança pode não ser necessária para todo o País, pois o instrumento requer uma abordagem local e depende dos estados e das bacias hidrográficas sujeitas aos riscos relacionados à água. Como a água é uma questão altamente local e regional, os mecanismos de precificação de água precisam ser abordados dentro do regional e não deve ser regulamentada em caráter setorial, pois provavelmente as decisões de investimentos relevantes teriam pouco impacto (Kablouti, 2014).

A cobrança representou um avanço na gestão de recursos, mas autores como Quental et al. (2010), argumentam que este instrumento sozinho não gera recursos suficientes para atender às necessidades de garantia de qualidade e disponibilidade de água na bacia. Segundo Hartmann (2010) e Acselrad et al. (2015) nas bacias onde a cobrança foi implementada os valores cobrados dos usuários são muito baixos, não favorecendo a mudança de comportamento, além de serem insuficientes para financiar todos os investimentos necessários para a resolução dos problemas nas respectivas bacias. De acordo com Brent e Ward (2019), um princípio fundamental na análise microeconômica é que os consumidores respondem a preços mais altos, reduzindo a quantidade demandada.

Desde a implementação da cobrança o montante arrecadado nas bacias interestaduais foi de 629,73 milhões de reais, sendo que o rio São Francisco representa $29 \%$ do total arrecadado (ANA, 2019). Os recursos arrecadados são aplicados em projetos previstos nos Planos de Recursos Hídricos. Dos valores arrecadados, 498,3 milhões já foram desembolsados em projetos de diversas naturezas, entretanto, os usuários pagadores ainda não reconhecem os benefícios do pagamento realizado o que reduz a legitimidade do instrumento (OCDE, 2017).

A arrecadação no Rio São Francisco desde a sua implementação em 2010 soma $R$ \$ 188,47 milhões de reais, com um desembolso de $\mathrm{R} \$ 135,25$ milhões de reais, representando aproximadamente $71 \%$ de execução (ANA, 2019). Os recursos são distribuídos conforme previsto no Plano de Aplicação, sendo divididos por grupos de ações: Ações de Gestão 38,1\%, Ações de Planejamento 16\% e Ações Estruturais 45,9\% (APV, 2019).

O Comitê da Bacia Hidrográfica do Rio São Francisco (CBHSF) atua buscando a sustentabilidade dos projetos que serão financiados com recursos da cobrança, o que pode ser verificado pelo constante aprimoramento dos seus procedimentos internos, como por exemplo, a aprovação de Deliberações que estabelecem critérios objetivos para seleção dos projetos. Além da criteriosa seleção dos projetos, é igualmente importante para o Comitê o processo de avaliação destes projetos, tanto pela ótica técnica, financeira e ambiental, quanto pela ótica social, ou seja, das populações beneficiadas. Para Coutinho et al. (2006), a avaliação da sustentabilidade de uma iniciativa, programa ou ação social é tarefa árdua, em função da dificuldade de se encontrarem indicadores que possam ser utilizados para tal mensuração.

De acordo com Sartori et al. (2014), a dimensão social recebeu menos atenção do ponto de vista político e acadêmico, sendo a dimensão menos explorada dos temas da sustentabilidade. Esse resultado está relacionado ao alto grau de subjetividade das suas variáveis e à falta de preocupação política aos seus aspectos. Neste contexto, o presente 
artigo tem como objetivo investigar a percepção social de atores do sistema de gestão da bacia e dos beneficiários diretos sobre os projetos financiados pelo CBHSF.

\section{A Bacia Hidrográfica do Rio São Francisco}

A Bacia Hidrográfica do Rio São Francisco abrange $639.219 \mathrm{~km}^{2}$ de área de drenagem e vazão média de $2.850 \mathrm{~m}^{3} / \mathrm{s}$ (MMA, 2007). Com, aproximadamente, $2.700 \mathrm{~km}$ de extensão, o rio São Francisco encontra-se totalmente inserido no território brasileiro, nasce na Serra da Canastra, em Minas Gerais e deságua no Oceano Atlântico, entre os municípios de Piaçabuçu (AL) e Brejo Grande (SE) (NEMUS, 2016).

A Bacia Hidrográfica do Rio São Francisco possui área em sete unidades da federação: Bahia (48,2\%), Minas Gerais (36,8\%), Pernambuco (10,9\%), Alagoas $(2,2 \%)$, Sergipe $(1,2 \%)$, Goiás $(0,5 \%)$ e Distrito Federal $(0,2 \%)$, e compreende 505 municípios (NEMUS, 2016). Em decorrência das suas características fisiográficas e peculiaridades regionais, a referida bacia hidrográfica foi dividida em quatro regiões: Alto, Médio, Submédio e Baixo São Francisco (Figura 1).

A produção de água da Bacia Hidrográfica do Rio São Francisco concentra-se nos cerrados da região central e em Minas Gerais e a grande variação do porte dos seus afluentes é consequência das diferenças climáticas entre as regiões drenadas.

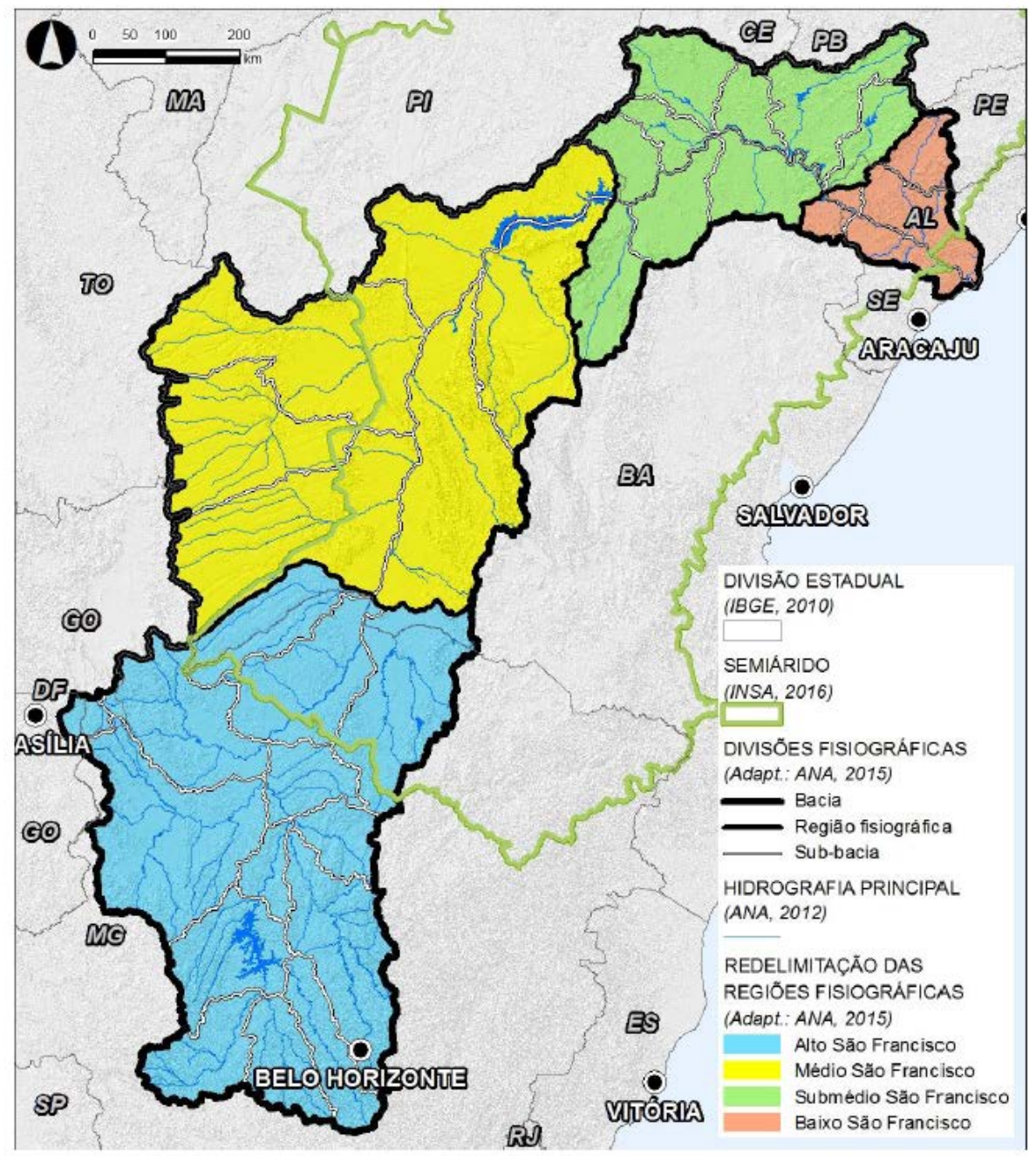

Figura 1. Regiões fisiográficas do rio São Francisco (NEMUS, 2016). 


\section{O Comitê da Bacia Hidrográfica do Rio São Francisco (CBHSF)}

O CBHSF foi criado por decreto presidencial em 5 de julho de 2001, a sua atual composição é formada por 62 membros titulares e seus respectivos suplentes, sendo $38,7 \%$ usuários de recursos hídricos, $32,2 \%$ poder público, $25,8 \%$ sociedade civil e 3,3\% comunidades tradicionais da bacia (https://cbhsaofrancisco.org.br/).

Os comitês de bacia são órgãos colegiados, consultivos e deliberativos e podem ser constituídos em bacias de rios de domínio estadual ou federal, com a finalidade de realizar a gestão descentralizada e participativa dos recursos hídricos da bacia. A participação ocorre justamente na constituição do comitê e no seu funcionamento interno, e isso faz com que as decisões sejam tomadas na instância mais próxima dos interessados (Morais et al., 2018).

As atividades institucionais do Comitê são exercidas pela Diretoria executiva e pela Diretoria colegiada. O Comitê possui câmaras técnicas (CT) e grupos de trabalho (GT) que subsidiam a tomada de decisões do plenário. O CBHSF possui os seguintes instrumentos de gestão: Plano de recursos hídricos - Plano Decenal (2004 a 2013) e Plano de Recursos Hídricos da Bacia Hidrográfica do São Francisco PRH-SF (2016 a 2025); cobrança pelo uso de recursos hídricos (2010 e 2017); sistema de informações sobre recursos hídricos e outorga de direito de recursos hídricos.

Para Novaes e Jacobi (2002), os comitês de bacia são importantes, pois são a base e também a linha de frente desse novo sistema de gestão. Sendo o comitê uma entidade com poder deliberativo, consultivo e normativo, os representantes devem estar bem articulados com seus representados, para conseguirem defender suas demandas de forma legítima e consistente.

De acordo com Monteiro (2009) é no âmbito destes novos arranjos de governança que a aprendizagem social se mostra como um referencial teórico/prático bem instrumentalizado para investigar e entender a participação de diferentes atores com vistas às tomadas de decisão. Este processo participativo amplia a legitimidade das escolhas públicas, fortalece a democracia e melhora as condições de governança.

\section{A cobrança na Bacia Hidrográfica do Rio São Francisco}

A cobrança pelo uso de recursos hídricos na bacia hidrográfica do rio São Francisco teve início em julho de 2010, de acordo com a Deliberação CBHSF no 40, de 31 de outubro de 2008. São cobrados os usos pela captação de água bruta, pelo consumo e pelo lançamento de efluentes nos corpos d'água. Somente são sujeitos à cobrança os usuários que possuem outorga de direito de uso dos recursos hídricos com captação de água superior a 4,0 L/s (ANA, 2019).

Em 2017, foi aprovada a Deliberação CBHSF no 94, que "atualiza, estabelece mecanismos e sugere novos valores de cobrança pelo uso de recursos hídricos na bacia hidrográfica do rio São Francisco", referendada pelo Conselho Nacional de Recursos Hídricos por meio da Resolução CNRH no 199/2018. A metodologia atual promoveu o aperfeiçoamento do instrumento da cobrança e trouxe mudanças, dentre as principais, destacam-se: fatores redutores somente serão aplicáveis nos casos em que o usuário demonstrar que possui boas práticas no uso da água, ou seja, as reduções não se aplicam mais a todos os usuários; revisão dos mecanismos de cobrança para o setor agropecuário e criação de mecanismo específico para situações de restrições hídricas (APV, 2018).

Os preços públicos unitários (PPU) aumentaram em 20\% para as parcelas captação e consumo (ANA, 2017). A previsão de arrecadação anual a partir da metodologia aprovada em 2017 é de $\mathrm{R} \$ 37.281 .656,30$ (captação e consumo). Desta forma, o valor médio cobrado será de aproximadamente $R \$ 0,0063 / \mathrm{m}^{3}$ (ANA, 2017). A Tabela 1 apresenta um resumo das metodologias (2008 e 2017) e os valores praticados pelo comitê. 
Tabela 1. Valores dos preços públicos unitários (PPU).

\begin{tabular}{|l|c|c|c|c|}
\hline \multirow{2}{*}{ Tipo de uso } & \multirow{2}{*}{ PPU } & \multirow{2}{*}{ Unidade } & \multicolumn{2}{|c|}{ Valor (R\$) } \\
\cline { 3 - 5 } & & $\mathrm{mU}_{\mathrm{cap}}$ & $\mathbf{2 0 0 8}$ & $\mathbf{2 0 1 7}$ \\
\hline Captação de água bruta & $\mathrm{mPU}_{\text {cons }}$ & $\mathrm{m}$ & 0,01 & 0,012 \\
\hline Consumo de água bruta & $\mathrm{PPU}_{\text {lanç }}$ & $\mathrm{R} \$ / \mathrm{kg} \mathrm{DBO}(5,20) / \mathrm{R} \$ / \mathrm{m}^{3}$ & 0,02 & 0,024 \\
\hline Lançamento de efluentes & \multicolumn{2}{|c|}{0,07} & $0,0012^{*}$ \\
\hline
\end{tabular}

*Vazão indisponibilizada. Fonte: Deliberação CBHSF no 40/2008 - Anexo II e Deliberação CBHSF nº 94/2017 - Anexo II.

São cobrados na Bacia Hidrográfica do Rio São Francisco cerca de três mil usuários, sendo o uso da transposição o mais representativo, com 50,1\% do valor total arrecadado, aproximadamente, $\mathrm{R} \$ 14.207 .465,00$; seguido pela captação com $28,01 \%$, ou $\mathrm{R} \$ 4.796 .265,00$; o consumo com $19,82 \%$, que representa $\mathrm{R} \$ 4.307 .315,00$ e o lançamento de efluentes com 1,76\% ou R\$415.094,00 (ANA, 2019). Na Tabela 2, são apresentados os valores repassados pela ANA e os desembolsos realizados pela Agência Peixe Vivo, de 2010 a 2018.

Tabela 2. Repasse dos recursos arrecadados com a cobrança (em R \$ milhões).

\begin{tabular}{|l|c|c|c|c|c|c|}
\hline Ano & $\begin{array}{c}\text { Repasse } \\
\text { (A) }\end{array}$ & $\begin{array}{c}\text { Desembolso } \\
\text { (B) }\end{array}$ & $\begin{array}{c}\text { \% } \\
\text { Desembolso (B/A) }\end{array}$ & $\begin{array}{c}\text { Rendimento } \\
\text { (C) }\end{array}$ & $\begin{array}{c}\text { \% } \\
\text { Desembolso } \\
\text { B/(A+C) }\end{array}$ & Saldo \\
\hline 2010 & 2,37 & 0,39 & $17 \%$ & 0,02 & $16 \%$ & 1,99 \\
\hline 2011 & 28,60 & 3,62 & $13 \%$ & 0,94 & $12 \%$ & 27,91 \\
\hline 2012 & 20,62 & 8,06 & $39 \%$ & 1,70 & $36 \%$ & 42,17 \\
\hline 2013 & 21,68 & 16,23 & $75 \%$ & 2,23 & $68 \%$ & 49,85 \\
\hline 2014 & 26,16 & 16,46 & $63 \%$ & 3,35 & $56 \%$ & 62,90 \\
\hline 2015 & 20,26 & 20,64 & $102 \%$ & 3,85 & $86 \%$ & 66,37 \\
\hline 2016 & 18,13 & 25,26 & $139 \%$ & 4,27 & $113 \%$ & 63,52 \\
\hline 2017 & 26,68 & 22,37 & $84 \%$ & 3,42 & $74 \%$ & 71,25 \\
\hline 2018 & 23,98 & 22,22 & $93 \%$ & 3,01 & $82 \%$ & 76,01 \\
\hline Total & 188,47 & 135,25 & $72 \%$ & 22,79 & $64 \%$ & 76,01 \\
\hline
\end{tabular}

Fonte: ANA (2019).

\section{Aplicação dos recursos da cobrança}

De acordo com o art. 44, da Lei no 9.433/1997, uma das atribuições das Agências de água (ou entidades delegatárias) é elaborar o plano de aplicação para os recursos arrecadados com a cobrança, para a apreciação e aprovação do respectivo comitê de bacia hidrográfica (Brasil, 1997). O plano de aplicação é um instrumento de planejamento financeiro que apresenta as possibilidades de investimentos nas diversas rubricas orçamentárias durante determinado período. Atualmente, na bacia hidrográfica do rio São Francisco, vigora o plano de aplicação plurianual (PAP) para o período de 2018 a 2020.

São financiados com os recursos da cobrança, os projetos de conservação e requalificação hidroambiental, os planos municipais de saneamento básico, estudos técnicos, atividades de educação ambiental, plano de comunicação e mobilização social, além de diversas outras ações previstas no plano de recursos hídricos e no PAP. 


\section{Material e métodos}

A pesquisa teve como foco a análise da percepção da população diretamente beneficiada pelos projetos executados pelo CBHSF com os recursos da cobrança. A primeira etapa consistiu na análise documental, na qual foram estabelecidos critérios visando à seleção dos projetos focos da pesquisa.

A etapa seguinte correspondeu a definição da população amostral, conforme Marino (2003), bem como a elaboração e aplicação de dois questionários (A e B), a tabulação dos dados e as análises dos resultados. O Questionário A é direcionado ao público interno ao Comitê e o Questionário B é direcionado às populações beneficiadas pelos projetos.

\section{Critérios para seleção dos projetos avaliados no presente estudo}

Para a seleção dos objetos da pesquisa, foram considerados 40 projetos, executados em todas as regiões da bacia, que totalizaram um investimento de $\mathrm{R} \$ 32.310 .605,16$, aproximadamente, $25 \%$ do total investido na bacia com recursos da cobrança. Foram estabelecidos quatro critérios, listados na Tabela 3.

Tabela 3. Critérios para seleção dos projetos.

\begin{tabular}{|c|c|c|c|c|}
\hline & & Definição & Justificativa & Peso \\
\hline \multirow{4}{*}{ 赵 } & 1 & $\begin{array}{l}\text { Projeto com valor superior } \\
\text { a } R \$ 2.000 .000,00\end{array}$ & $\begin{array}{l}\text { Quanto maior o valor investido no projeto, maior a } \\
\text { necessidade de transparência e fiscalização na utilização } \\
\text { do recurso público. Representam a menor parcela de } \\
\text { projetos, aproximadamente } 5 \% \text {, em relação ao total de } \\
\text { projetos executados na bacia. }\end{array}$ & 1 \\
\hline & 2 & $\begin{array}{l}\text { Projeto com período de } \\
\text { execução superior a } 24 \\
\text { meses }\end{array}$ & $\begin{array}{l}\text { Projetos com maior prazo de duração permanecem por } \\
\text { mais tempo na região, tendo maior possibilidade de } \\
\text { mobilizar instituições e a população em geral. }\end{array}$ & 1 \\
\hline & 3 & $\begin{array}{l}\text { Projeto desenvolvido para } \\
\text { comunidades tradicionais } \\
\text { da bacia hidrográfica do } \\
\text { rio São Francisco }\end{array}$ & $\begin{array}{l}\text { Comunidades tradicionais, normalmente, utilizam } \\
\text { práticas conservacionistas de manejo, contribuindo com } \\
\text { a preservação das águas e manutenção do equilíbrio } \\
\text { ambiental, além de preservar a cultura ribeirinha. }\end{array}$ & 1 \\
\hline & 4 & $\begin{array}{l}\text { Projeto que demonstre a } \\
\text { capacidade de articulação } \\
\text { do Comitê }\end{array}$ & $\begin{array}{l}\text { Participação de, no mínimo, duas instituições externas } \\
\text { durante a execução do projeto. O fato de agregar } \\
\text { parceiros externos pode indicar uma maior chance de } \\
\text { manutenção do projeto, além de aumentar a percepção } \\
\text { social sobre os resultados. }\end{array}$ & 1 \\
\hline
\end{tabular}

Após a aplicação dos critérios foram selecionados dois projetos, que obtiveram a maior pontuação, um deles alcançou quatro pontos e outro três pontos.

\section{Projeto 1}

Título: Recuperação hidroambiental na Bacia do Rio Curituba.

Localização: Assentamento Mandacaru - Canindé de São Francisco (SE).

Região: Baixo São Francisco.

População beneficiada: 60 famílias residentes, aproximadamente 240 pessoas.

Resultados: Intervenções e plantios por uma extensão de 2,5 km ao longo do rio Curituba e nas áreas adjacentes ao curso d'água; recuperação de áreas de preservação 
permanente (APP) e áreas de reserva legal; cercamento de áreas de reserva legal e plantio irrigado de mudas dentro da área de preservação permanente no entorno do rio Curituba. Realização de ações de mobilização social, educação ambiental e capacitação. Na execução do projeto foram construídas 155 barraginhas, $14 \mathrm{~km}$ de cercas e recuperação de 23 ha de áreas degradadas, plantio de 19 mil mudas nativas da caatinga, construção de bacias de contenção, entre outras intervenções.

O rio Curituba possui uma grande importância para o município de Canindé de São Francisco, sendo utilizado pelas famílias dos assentamentos rurais do seu entorno como fonte principalmente para dessedentação de animais, mesmo havendo alto grau de salinidade (Aguiar Netto e Santana, 2015).

\section{Projeto 2}

Título do Projeto: Implantação do Sistema de Abastecimento de Água (SAA) da Aldeia Serrote dos Campos.

Localização: Aldeia Serrote dos Campos - Zona Rural - Itacuruba (PE).

Região: Submédio São Francisco.

População beneficiada: 71 famílias, aproximadamente 450 pessoas.

Resultados: Construção de ligações domiciliares, redes de distribuição, adutora, elevatória, linhas de recalque e estação de tratamento. Implantação de sistema de irrigação com conjunto de estruturas e equipamentos para captação, adução, armazenamento, distribuição e aplicação de água em culturas. A obra foi projetada para atender a população por um período de 20 anos.

\section{Instrumento para coleta de dados - Questionário}

Para a coleta de dados foram elaborados dois questionários, denominados Questionário A e Questionário B. Possuem abordagens distintas e tem como objetivo investigar a percepção dos resultados dos projetos, considerando as múltiplas visões e múltiplos atores envolvidos. 0 Questionário A possui 65 perguntas (62 de múltipla escolha e três dissertativas), agrupadas em onze blocos, foi elaborado visando o público interno do comitê. Já o Questionário B possui 21 perguntas (20 perguntas de múltipla escolha e uma dissertativa) e teve foco nas populações beneficiadas pelos projetos. 0 total da amostra foi 90, sendo 81 questionários A e nove questionários B, com a obtenção de 86 respostas.

\section{Resultados e discussão}

O Projeto 1 - Recuperação hidroambiental na Bacia do Rio Curituba, beneficiou cerca de 240 pessoas e o Projeto 2 - Implantação do sistema de abastecimento de água da Aldeia Serrote dos Campos, atendeu à uma população de mais de 400 indígenas.

Foi utilizada a técnica de análise de conteúdo, comumente adotada em pesquisas qualitativas proposta por Bardin (2011). Na Tabela 4 são apresentados os resultados do Questionário A e na Tabela 5 os resultados do Questionário B. Após cada tabela, foi feita a discussão dos temas mais relevantes destacados pela pesquisa.

\section{Avaliação do público interno ao comitê de bacia hidrográfica}

Foi aplicado a membros titulares do CBHSF (62), membros de câmaras técnicas (15) e representantes das empresas executoras dos projetos (04), totalizando 81 questionários enviados e 77 respostas. Na Tabela 4 são apresentados os temas abordados e os resultados obtidos. 
Tabela 4. Resultados do Questionário A.

\begin{tabular}{|c|c|c|}
\hline Bloco & Tema e perguntas & Resultados \\
\hline$\overline{1}$ & $\begin{array}{l}\text { Preliminares } \\
\text { Representatividade do entrevistado no comitê }\end{array}$ & $\begin{array}{l}70 \% \text { membros titulares do } \\
\text { CBHSF } \\
30 \% \\
\text { técnicas/empresas } \\
\end{array}$ \\
\hline 2 & $\begin{array}{l}\text { Plano de Recursos Hídricos } \\
10 \text { perguntas: aspectos técnicos e institucionais } \\
\text { envolvidos na elaboração e acompanhamento da } \\
\text { execução do Plano; qualificação dos membros do Comitê } \\
\text { para realizar o acompanhamento; qualidade técnica e } \\
\text { administrativa da empresa executora; papel do órgão } \\
\text { gestor de recursos hídricos e existência de mecanismos } \\
\text { de acompanhamento do Plano pelo Comitê. }\end{array}$ & $\begin{array}{l}\text { 85\% consideram o Plano de } \\
\text { Recursos Hídricos um } \\
\text { instrumento importante para } \\
\text { a gestão da bacia; } \\
\text { 87\% afirmam terem lido o } \\
\text { Plano; } \\
60 \% \text { acreditam que é } \\
\text { importante a participação do } \\
\text { comitê na elaboração e } \\
\text { implementação do Plano; } \\
30 \% \text { acham que os membros } \\
\text { do CBHSF não estão } \\
\text { qualificados para acompanhar } \\
\text { a elaboração e implementação } \\
\text { do Plano; acro a } \\
60 \% \text { acreditam que a } \\
\text { participação do órgão gestor } \\
\text { no acompanhamento do Plano } \\
\text { é fator importante no } \\
\text { resultado; } \\
\text { 53\% afirmam que o CBHSF } \\
\text { não possui mecanismos de } \\
\text { acompanhamento do Plano. } \\
\end{array}$ \\
\hline 3 & $\begin{array}{l}\text { Plano de Aplicação Plurianual (PAP) } \\
9 \text { perguntas: conhecimento técnico dos membros do } \\
\text { Comitê; relação do PAP com o Plano de Recursos } \\
\text { Hídricos; competência técnica da Agência; importância da } \\
\text { interação dos funcionários da Agência com membros do } \\
\text { Comitê e participação do órgão gestor. }\end{array}$ & $\begin{array}{l}\text { 98\% conhecem o PAP e o } \\
\text { associam ao plano de recursos } \\
\text { hídricos da bacia; } \\
\text { 85\% consideram importante a } \\
\text { competência dos técnicos da } \\
\text { agência e a interação destes } \\
\text { com os membros do comitê; } \\
70 \% \text { consideram que a } \\
\text { participação do órgão gestor } \\
\text { nas discussões sobre o PAP } \\
\text { garante qualidade técnica. }\end{array}$ \\
\hline
\end{tabular}


Tabela 4. Continuação.

\begin{tabular}{|c|c|c|}
\hline Bloco & $\begin{array}{l}\text { Tema e perguntas } \\
\end{array}$ & Resultados \\
\hline 4 & $\begin{array}{l}\text { Seleção dos Projetos } \\
9 \text { perguntas: estratégia de seleção dos projetos; } \\
\text { aspectos técnicos e políticos envolvidos na seleção dos } \\
\text { projetos; relação dos projetos selecionados com o PAP; } \\
\text { aderência dos projetos ao Plano de Recursos Hídricos; } \\
\text { estratégia de comunicação para divulgação dos } \\
\text { projetos; participação do órgão gestor e consulta à } \\
\text { população beneficiada sobre a necessidade do projeto. }\end{array}$ & $\begin{array}{l}63 \% \text { consideram que a seleção } \\
\text { dos projetos feita pela CCR leva } \\
\text { em conta aspectos políticos e } \\
\text { regionais, além dos técnicos; } \\
70 \% \text { afirmam que o órgão gestor } \\
\text { não avalia os projetos } \\
\text { selecionados, visando evitar } \\
\text { superposição de ações; } \\
44 \% \text { dizem que a população } \\
\text { local raramente é consultada } \\
\text { sobre a pertinência } \\
\text { necessidade do projeto; } \\
67 \% \text { acreditam que a } \\
\text { mobilização e a comunicação } \\
\text { dos projetos não atingem o } \\
\text { público de forma geral; } \\
60 \% \text { acreditam que os projetos } \\
\text { tem aderência ao PRH; } \\
70 \% \text { acreditam que os projetos } \\
\text { possuem relação com o PAP. }\end{array}$ \\
\hline 5 & $\begin{array}{l}\text { Contratação dos Projetos } \\
3 \text { perguntas: contratação dos projetos pela Agência; se } \\
\text { a forma adotada para contratação garante qualidade, } \\
\text { preço e agilidade aos projetos; se Agência propõe } \\
\text { indicadores de efetividade nos projetos para que os } \\
\text { resultados possam ser medidos e avaliados. }\end{array}$ & $\begin{array}{l}13 \% \text { dizem conhecer os } \\
\text { procedimentos de contratação } \\
\text { realizados pela agência; } \\
57 \% \text { discordam que a forma } \\
\text { adotada garanta uma } \\
\text { contratação com qualidade; } \\
\text { 80\% afirmam que a agência não } \\
\text { propõe indicadores para avaliar } \\
\text { a efetividade da ação. }\end{array}$ \\
\hline 6 & $\begin{array}{l}\text { Implementação dos Projetos } \\
4 \text { perguntas: conhecimento dos atores locais e processo } \\
\text { de comunicação realizado pela empresa executora; } \\
\text { mobilização social e divulgação dos projetos pelo } \\
\text { Comitê. }\end{array}$ & $\begin{array}{l}70 \% \text { afirmam que as empresas } \\
\text { contratadas não conhecem os } \\
\text { atores sociais da bacia e não } \\
\text { trabalham de forma alinhada à } \\
\text { visão institucional do CBHSF; } \\
57 \% \text { acreditam que a } \\
\text { comunicação do CBHSF } \\
\text { raramente divulga os projetos } \\
\text { em execução de forma } \\
\text { adequada. }\end{array}$ \\
\hline 7 & $\begin{array}{l}\text { Acompanhamento e Fiscalização do Projeto } \\
8 \text { perguntas: fiscalização dos projetos; forma de } \\
\text { atuação da agência e comitê durante a fiscalização do } \\
\text { projeto; acompanhamento pelo Comitê e suas } \\
\text { instâncias, órgão gestor e os beneficiários dos projetos; } \\
\text { existência de indicadores nos projetos. }\end{array}$ & $\begin{array}{l}50 \% \text { dizem que raramente a } \\
\text { agência acompanha os projetos } \\
\text { de forma adequada; } \\
65 \% \text { afirmam que o comitê e } \\
\text { suas instâncias acompanham os } \\
\text { projetos; } \\
75 \% \text { afirmam que não existem } \\
\text { indicadores nos projetos. }\end{array}$ \\
\hline
\end{tabular}


Tabela 4. Continuação.

\begin{tabular}{|c|c|c|}
\hline Bloco & Tema e perguntas & Resultados \\
\hline 8 & $\begin{array}{l}\text { Conclusão e entrega do projeto } \\
6 \text { perguntas: Agência avalia os impactos dos projetos } \\
\text { para a bacia; Agência possui equipe suficiente para } \\
\text { monitorar os projetos; existe metodologia de } \\
\text { acompanhamento dos projetos; envolvimento dos } \\
\text { beneficiários é garantia de manutenção do projeto; } \\
\text { quem deverá ser responsável pela manutenção do } \\
\text { projeto. }\end{array}$ & $\begin{array}{l}63 \% \text { afirmam que a agência e o } \\
\text { comitê não possuem metodologia } \\
\text { para acompanhamento dos } \\
\text { projetos; } \\
84 \% \text { dizem que a agência não } \\
\text { avalia o impacto do projeto para } \\
\text { a bacia; } \\
88 \% \text { acreditam que a agência não } \\
\text { possui equipe suficiente para } \\
\text { acompanhar os projetos; } \\
54 \% \text { acreditam que } \\
\text { envolvimento dos demandantes e } \\
\text { membros da CCR garante } \\
\text { parcialmente a manutenção dos } \\
\text { projetos; } \\
90 \% \text { afirmam que o beneficiário } \\
\text { deve se responsabilizar pela } \\
\text { manutenção do projeto. }\end{array}$ \\
\hline 9 & $\begin{array}{l}\text { Resultados do projeto } \\
6 \text { perguntas: conhecimento sobre os resultados } \\
\text { obtidos; resultados atenderam às expectativas do } \\
\text { CBHSF e da população beneficiada; houve melhoria na } \\
\text { qualidade ou quantidade de água na região do projeto; } \\
\text { resultados contribuíram para atingir as metas } \\
\text { previstas no Plano de Recursos Hídricos; projeto } \\
\text { proporcionou maior visibilidade ao CBHSF. }\end{array}$ & $\begin{array}{l}65 \% \text { não sabem responder sobre } \\
\text { a melhoria da qualidade e/ou } \\
\text { quantidade de água na região do } \\
\text { projeto; } \\
74 \% \text { não sabem se o projeto } \\
\text { atendeu às expectativas da } \\
\text { população beneficiada; } \\
64 \% \text { não sabem se os projetos } \\
\text { deram maior visibilidade ao } \\
\text { comitê. }\end{array}$ \\
\hline 10 & $\begin{array}{l}\text { Sugestões: } \\
\text { a) } 0 \text { que você sugere para aprimorar o desempenho } \\
\text { dos projetos executados no âmbito do PAP? } \\
\text { b) De que forma a sociedade poderia desempenhar um } \\
\text { papel mais efetivo durante o acompanhamento e } \\
\text { fiscalização dos projetos? } \\
\text { c) Sugira indicadores para acompanhamento da } \\
\text { efetividade de projetos executados na bacia } \\
\text { hidrográfica. }\end{array}$ & $\begin{array}{l}\text { a) Indicadores pós-projeto; } \\
\text { monitoramento } \\
\text { acompanhamento das metas a } \\
\text { serem alcançadas; } \\
\text { acompanhamento e fiscalização. } \\
\text { b) Se informando; ser parte } \\
\text { integrante dos projetos, com } \\
\text { alguma atividade ou } \\
\text { contrapartida; participando das } \\
\text { reuniões do comitê. } \\
\text { c) Atendimento ao previsto no } \\
\text { Plano da Bacia; benefício da } \\
\text { população; recuperação } \\
\text { ambiental bacia; } \\
\text { sustentabilidade temporal; } \\
\text { reconhecimento social. }\end{array}$ \\
\hline
\end{tabular}


Tabela 4. Continuação.

\begin{tabular}{|l|l|l|l|}
\hline Bloco & \multicolumn{1}{|c|}{ Tema e perguntas } & \multicolumn{1}{c|}{ Resultados } \\
\cline { 2 - 4 } & $\begin{array}{l}\text { Perfil do entrevistado } \\
\text { 4 perguntas: idade, escolaridade, renda e sexo. 0 } \\
\text { objetivo é conhecer o perfil da amostra pesquisada. A } \\
\text { identidade do entrevistado não foi solicitada. }\end{array}$ & $\begin{array}{l}\text { 66\% entre 36 55 anos; } \\
62 \% \text { formação superior; } \\
\text { mínimos; renda de 5 a } 7 \text { salários } \\
4 \% \text { feminino e 53\% masculino. }\end{array}$ \\
\hline
\end{tabular}

Programas de Formação Continuada: Os resultados apontam a necessidade de promover treinamentos específicos para os membros de comitês de bacias para que exerçam de forma qualificada a função de conselheiro e possam acompanhar as ações promovidas pelo comitê, inclusive as questões técnicas. 0 órgão gestor torna-se fundamental neste aspecto, pois, possui capacidade técnica e financeira para promover esta ação em parceria com o comitê e a agência. Considerando a renovação na composição dos Comitês é importante que as capacitações/cursos/treinamentos tenham caráter permanente e que façam parte de um programa amplo e continuado.

Articulação Institucional: Como previsto na Lei no 9.433/1997, art. 38, inciso I, é competência dos comitês de bacia, "promover o debate das questões relacionadas a recursos hídricos e articular a atuação das entidades intervenientes". Os resultados indicam que o comitê deverá atuar promovendo a integração entre os atores da gestão hídrica da bacia, desde a elaboração do PAP e seleção dos projetos prioritários até a etapa de execução dos projetos.

Conhecimento Técnico: Os resultados demonstram que os membros do comitê consideram importante o suporte da agência e do órgão gestor como fator de garantia da qualidade técnica das ações. Porém, na prática, 63\% consideram que a seleção dos projetos leva em conta aspectos políticos e regionais, além dos técnicos. Portanto, deve-se considerar que, para que o plano de aplicação dos recursos gere resultados efetivos, este deverá ser embasado em critérios técnicos muito bem delimitados. Importante seguir as ações previstas no plano de recursos hídricos e aprovar regras e critérios objetivos e transparentes.

Papel do órgão gestor: Os resultados apontam a necessidade de maior integração entre o órgão gestor, o comitê e a agência. Atuando em conjunto, o órgão gestor poderá apoiar tecnicamente as ações e avaliar os projetos de modo mais amplo, além de evitar a sobreposição de ações na bacia. O CBHSF poderá contribuir intensificando a atuação de sua Câmara Técnica de Articulação Institucional (CTAI), formada por representantes dos órgãos gestores estaduais e das CCR, para que esta compartilhe as informações sobre as ações definidas pelo comitê.

Comunicação Institucional: Os resultados indicam que as formas de comunicação utilizadas devem ser aperfeiçoadas, com o objetivo de aumentar a visibilidade e a percepção dos membros do comitê e da sociedade em relação às ações executadas na bacia. É recomendado o desenvolvimento de mecanismos de comunicação que atinjam todos os tipos de público, tanto interno, quanto externo, além de estreitar o relacionamento com veículos locais de comunicação para o compartilhamento de informações sobre as atividades do Comitê. 
Indicadores de efetividade: A pesquisa demonstra a necessidade de inserir indicadores para melhor acompanhamento e avaliação dos projetos executados. A ausência de indicadores de efetividade nos projetos pode criar uma fragilidade em relação à credibilidade das ações do comitê e da agência. É recomendável que a agência estabeleça indicadores e os inclua nos Termos de Referência para contratação dos projetos. Desta forma, a empresa executora terá que demonstrar e mensurar os resultados obtidos e, a partir desta análise, os membros do comitê poderão aprimorar as formas de seleção dos projetos, optando-se por aqueles que apresentem maior impacto positivo para a bacia. Os projetos deverão conter indicadores físicos e financeiros, como por exemplo, o atendimento dos prazos e valores contratados e a melhoria da disponibilidade hídrica na região, além de indicadores sociais, como o atendimento das expectativas da população beneficiada e a sustentabilidade dos projetos.

Acompanhamento do Plano de Recursos Hídricos: Os resultados indicam que o comitê não possui mecanismos de acompanhamento das ações previstas no Plano, o que pode demonstrar uma falta de clareza sobre os papéis que cada ente desempenha no Sistema. A competência pelo acompanhamento e fiscalização das ações do Plano é da agência, que deverá estabelecer procedimentos claros e divulgá-los amplamente aos membros do Comitê. 0 papel do comitê é complementar ao papel da agência e também deve ser definido com clareza. No caso do CBHSF, por exemplo, cada CCR possui uma comissão de acompanhamento de projetos, além disso, o comitê possui o Grupo de Acompanhamento do Contrato de Gestão (GACG), que podem atuar de forma mais articulada.

Beneficiários dos Projetos: 0 resultado da pesquisa indica que a participação da população beneficiada durante a implantação do projeto favorece o sucesso das ações. A pesquisa mostra que $90 \%$ dos entrevistados consideram que os beneficiários devem ser os responsáveis pela manutenção dos projetos, portanto, seria recomendável estabelecer previamente as responsabilidades dos envolvidos.

\section{Avaliação da população beneficiada pelos projetos}

Foi aplicado a nove lideranças das comunidades beneficiadas (seis no Projeto $1 \mathrm{e}$ três no Projeto 2), todos foram respondidos. Na Tabela 5, a seguir, são apresentados os resultados.

Os resultados obtidos com o Questionário B demonstram que as comunidades beneficiadas se consideram inseridas no processo; que foram consultadas sobre a necessidade dos projetos; se declaram satisfeitas com os resultados; afirmam que o CBHSF consolida sua atuação na bacia investindo em projetos de recuperação ambiental e dizem ter conhecimento do plano de recursos hídricos da bacia. Além disso, consideram que as comunidades beneficiadas devem ser as responsáveis pela manutenção dos projetos.

As sugestões apresentadas pelos entrevistados reforçam a necessidade de melhorar a comunicação e a divulgação das ações; realizar mais ações de mobilização social; executar ações com a comunidade e fiscalizar de forma mais eficiente o projeto. Estas sugestões vão ao encontro das observações feitas no estudo de Macedo e Magalhães Júnior (2011), onde foi constatado que a interação entre os atores sempre pode ser fortalecida, por exemplo, com mais informação, conscientização e educação. 
Tabela 5. Resultados do Questionário B.

\begin{tabular}{|c|c|c|}
\hline Temas & Projeto 1 & Projeto 2 \\
\hline $\begin{array}{l}\text { São ou foram membros de comitê } \\
\text { de bacia }\end{array}$ & $100 \%$ não & $60 \% \operatorname{sim}$ \\
\hline $\begin{array}{l}\text { Conhecem o Plano de Recursos } \\
\text { Hídricos (PRH) }\end{array}$ & $66 \%$ conhece o PRH & $60 \%$ conhece o PRH \\
\hline $\begin{array}{l}\text { Projeto atende às expectativas da } \\
\text { comunidade }\end{array}$ & $83 \%$ atende & $100 \%$ atende \\
\hline $\begin{array}{l}\text { Houve melhoria na qualidade ou } \\
\text { quantidade de água na região do } \\
\text { projeto }\end{array}$ & $66 \% \operatorname{sim}$ & $20 \% \operatorname{sim}$ \\
\hline $\begin{array}{l}\text { Responsabilidade sobre a } \\
\text { manutenção do projeto }\end{array}$ & $\begin{array}{ll}100 \% & \text { beneficiário } \\
\text { responsável pela manutenção } \\
\text { do projeto. }\end{array}$ & $\begin{array}{lr}100 \% & \text { beneficiário } \\
\text { responsável } & \text { pela } \\
\text { manutenção do projeto. }\end{array}$ \\
\hline $\begin{array}{l}\text { Sugestões para aprimorar os } \\
\text { resultados }\end{array}$ & $\begin{array}{l}\text { Realizar mais ações de } \\
\text { mobilização e acompanhar as } \\
\text { intervenções; } \\
\begin{array}{lll}\text { Melhorar as capacitações } & \\
\text { executar ações com a } \\
\text { comunidade. }\end{array}\end{array}$ & $\begin{array}{l}\text { Melhorar a agilidade; } \\
\text { Fiscalizar melhor o projeto; } \\
\text { Melhorar a comunicação e } \\
\text { divulgação das ações. }\end{array}$ \\
\hline
\end{tabular}

Pelos resultados da pesquisa, pode-se afirmar que a percepção dos beneficiários em relação aos projetos pesquisados é positiva. No entanto, este resultado não significa que todos os projetos financiados pelo CBHSF foram bem aceitos pelas comunidades, mas sinalizam que os projetos estudados nesta pesquisa tiveram a condução adequada em relação aos beneficiários.

\section{Conclusão}

Da mesma forma que o cenário mais amplo das outras bacias hidrográficas interestaduais, o comitê da bacia hidrográfica do rio São Francisco ainda não possui mecanismos para avaliação da percepção das partes interessadas em relação à efetividade da aplicação dos recursos arrecadados pela cobrança. 0 atual acompanhamento realizado pelo CBHSF, Agência Peixe Vivo e Agência Nacional de Águas está focado em avaliações dos resultados físico-financeiros e não na relevância social e significado destes resultados.

Na pesquisa foram elencadas algumas ações que podem ser aprimoradas visando ao fortalecimento da gestão hídrica na bacia do rio São Francisco. Entre elas, destaca-se a necessidade de oferecer programas de capacitação e formação continuada, para que os membros do comitê possam exercer de forma adequada suas funções; o fortalecimento da articulação institucional feita pelo comitê, buscando agregar maior número de parceiros nas ações; a ampliação da comunicação institucional, para que as ações tenham maior visibilidade e a adoção de indicadores para o acompanhamento da efetividade nos projetos.

Muito ainda se pode avançar na gestão de recursos hídricos, especialmente em relação à cobrança pelo uso da água, cuja implementação deverá ser incentivada ao maior número possível de bacias hidrográficas, incentivando a racionalização do uso e incrementando o aporte de recursos financeiros para investimentos nas ações de recomposição, preservação e melhoria hidroambiental. 


\section{Conflito de interesses}

Os autores declaram não haver conflito de interesses.

\section{Referências}

Acselrad, M. V.; Azevedo, J. P. S. A.; Formiga-Johnsson, R. M. Cobrança pelo uso da água no Estado do Rio de Janeiro, Brasil (2004-2013): histórico e desafios atuais. Engenharia Sanitária e Ambiental, v. 20, n. 2, p. 199-208, 2015. https://doi.org/10.1590/S141341522015020000112026

Aguiar Netto, A. O.; Santana, N. R. F. (Orgs.). Contexto socioambiental das águas do Rio São Francisco. São Cristóvão: Editora UFS, 2015.

ANA - Agência Nacional de Águas. Cobrança pelo Uso de Recursos Hídricos. Brasília: ANA, 2014. (Cadernos de Capacitação em Recursos Hídricos, v. 7).

ANA - Agência Nacional de Águas. Cobrança pelo uso de recursos hídricos na Bacia Hidrográfica do Rio São Francisco. Brasília: ANA, 2010. (Nota Técnica no 06/2010/SAGANA).

ANA - Agência Nacional de Águas. Conjuntura dos Recursos Hídricos no Brasil 2019. Brasília: ANA, 2019. (Encarte: Cobrança pelo uso dos recursos hídricos).

ANA - Agência Nacional de Águas. Subsídios ao CNRH para definição dos mecanismos e valores a serem cobrados pelo uso de recursos hídricos de domínio da União na Bacia Hidrográfica do Rio São Francisco. Brasília: ANA, 2017. (Nota Técnica no 07/2017/CSCOB/SAS).

APV - Agência de Bacia Hidrográfica Peixe Vivo. Relatório de Gestão. Belo Horizonte: APV, 2018.

Assis, W. D.; Ribeiro, M. M. R.; Moraes, M. M. G. A. Proposição de melhorias para o Sistema de Cobrança pelo Uso da Água Bruta da Bacia Hidrográfica do Rio São Francisco. $\begin{array}{llllll}\text { Engenharia Sanitária e Ambiental, } & \text { v. 23, } & \text { n. 4, } & \text { p.779-790, } 2018 .\end{array}$ https://doi.org/10.1590/S1413-41522018163489

Barcellos, F. C.; Acselrad, M. V.; Costa, V. G. Efetividade na aplicação de recursos obtidos com a cobrança pelo uso da água bruta na porção fluminense da Bacia do Paraíba do Sul. Revista Iberoamericana de Economía Ecológica, v. 16/17, p. 1-15, 2011.

Bardin, L. Análise de conteúdo. Lisboa: Edições 70, 2011.

Brasil. Constituição da República Federativa do Brasil de 1988. Disponível: <http://www.planalto.gov.br/ccivil_03/constituicao/constituicao.htm>. Acesso em: 24 abr. 2020.

Brasil. Lei no 9.433, de 8 de janeiro de 1997. Institui a Política Nacional de Recursos Hídricos, cria o Sistema Nacional de Gerenciamento de Recursos Hídricos, regulamenta o inciso XIX do art. 21 da Constituição Federal, e altera o art. 1o da Lei no ${ }^{\circ}$ 8.001, de 13 de março de 1990, que modificou a Lei no 7.990, de 28 de dezembro de 1989. Disponível: <http://www.planalto.gov.br/ccivil_03/leis/19433.htm>. Acesso em: 24 abr. 2020. 
Brent, D. A.; Ward, M. B. Price perceptions in water demand. Journal of Environmental Economics and Management, v. 99, 102266, 2019. https://doi.org/10.1016/j.jeem.2019. 102266

Brito, M. C. L. D. A.; Aguiar, J. C. A cobrança pelo uso da água como instrumento de gestão de recursos hídricos. Revista Direito Ambiental e Sociedade, v. 9, p. 61-90, 2019.

Coutinho, R. B. G.; Macedo-Soares, T. D. L. V. A.; Silva, J. R. G. Projetos sociais de empresas no Brasil: arcabouço conceitual para pesquisas empíricas e análises gerenciais. Revista de Administração Pública, v. 40, n. 5, p. 763-787, 2006. https://doi.org/10.1590/S003476122006000500002

Finkler, N. R.; Mendes, L. A.; Bortolin, T. A.; Schneider, V. E. Cobrança pelo uso da água no Brasil: uma revisão metodológica. Desenvolvimento Meio Ambiente, v. 33, p. 33-49, 2015. http://doi.org/10.5380/dma.v33i0.36413

Hartmann, P. A cobrança pelo uso da água como instrumento econômico na política ambiental: estudo comparativo e avaliação econômica dos modelos de cobrança pelo uso da água bruta propostos e implementados no Brasil. Porto Alegre: AEBA, 2010.

Kablouti, G. Cost of water use: A driver of future investments into water-efficient thermal power plants? Aquatic Procedia, v. 5, p. 31-43, 2015. https://doi.org/10.1016/j.aqpro. 2015.10.006

Macedo, D. R.; Magalhães Júnior, A. P. M. Percepção social no programa de restauração de cursos d'água urbanos em Belo Horizonte. Sociedade \& Natureza, v. 23, n. 1, p. 51-63, 2011.

Magalhães Júnior, A. P.; Nunes Júnior, T. T. Perspectivas de efetivação da cobrança pelo uso da água no Brasil com base no caso da porção mineira da Bacia do Paraíba do Sul. Revista Brasileira de Recursos Hídricos, v. 14, n. 3, p. 17-26, 2009. http://doi.org/10.21168/ rbrh.v14n3.p17-26

Marino, E. Manual de avaliação de projetos sociais. 2. ed. São Paulo: Instituto Airton Senna, Saraiva, 2003.

MMA - Ministério do Meio Ambiente. Brasil: recursos hídricos. Brasília: MMA/ANA/PNUD, 2007.

Monteiro, F. Para além da participação: aprendizagem social na gestão dos recursos hídricos. São Paulo: Universidade de São Paulo, 2009. (Tese de doutorado).

Morais, J. L. M.; Fadul, E.; Cerqueira, L. S. Limites e desafios na gestão de recursos hídricos por comitês de bacias hidrográficas: um estudo nos estados do Nordeste do Brasil. REAd, v. 24, p. 238-264, 2018. http://doi.org/10.1590/1413-2311.187.67528

NEMUS. Plano de Recursos Hídricos da Bacia Hidrográfica do Rio São Francisco 2016-2025. RP1A - Diagnóstico da Dimensão Técnica e Institucional. Nemus, Gestão e Requalificação, 2016. v. 1 e 2.

Novaes R. C.; Jacobi, P. R. Comitês de Bacia, capital social e eficiência institucional: reflexões preliminares sobre influências recíprocas. Anais do Encontro Nacional ANPPAS, 2002.

OCDE - Organização para Cooperação e Desenvolvimento Econômico. Cobranças pelo uso de recursos hídricos no Brasil: Caminhos a seguir. Paris: Éditions OCDE, 2017. https://doi.org/10.1787/9789264288423-pt 
Quental, S.; Bombo, I.; Yansen, K. Aplicação dos recursos arrecadados pelas cobranças PCJ em PDCs e investimentos. Anais do Simpósio Experiências em Gestão dos Recursos Hídricos por Bacia Hidrográfica, Atibaia, 2010.

Sartori, S.; Latrônico, F.; Campos, L. M. S. Sustentabilidade e desenvolvimento sustentável: uma taxonomia no campo da literatura. Ambiente \& Sociedade, v. 17, p. 1-22, 2014. 